\title{
Minithoracotomy vs. Conventional Mitral Valve Surgery for Rheumatic Mitral Valve Stenosis: a Single-Center Analysis of 128 Patients
}

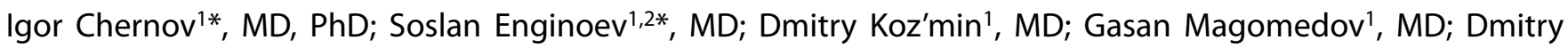
Tarasov ${ }^{1}, \mathrm{MD}$, PhD; Michel Pompeu B. O. Sá ${ }^{3}, \mathrm{MD}$, MSc, PhD; Alexander Weymann ${ }^{4}$ MD, PhD, FECTS, FESC; Konstantin Zhigalov ${ }^{4}$, MD

\section{Abstract}

Objective: To compare the in-hospital outcomes of a right-sided anterolateral minithoracotomy with those of median sternotomy in patients who received a mitral valve replacement (MVR) because of rheumatic mitral valve stenosis (RMS).

Methods: This is a retrospective analysis of 128 patients (34\% male) with RMS between 2011 and 2015. The median age was 53 years $(45 ; 56)$. The mean ejection fraction was $58.4 \pm 6.3 \%$. All the subjects were divided into two groups - Group 1 contained 78 patients who underwent MVR via minithoracotomy (MT-MVR), while Group 2 contained 50 patients who underwent MVR via median sternotomy (S-MVR).

Results: In the MT-MVR group, a mechanical prosthesis was implanted in $72 \%$ of cases, while it was implanted in $90 \%$ of cases in the S-MVR group $(P=0.01)$. The duration of myocardial ischemia was similar (MT-MVR, 77 $\pm 24 \mathrm{~min}$; S-MVR, 70 $\pm 18 \mathrm{~min}$ ) $(P=0.09)$. However, the cardiopulmonary bypass time was lower in the S-MVR group than in the MT-MVR group $(99 \pm 24 \mathrm{~min}$ and $119 \pm 34 \mathrm{~min}$, respectively) $(P \leq 0.001)$. There was no difference in the duration of mechanical ventilation, intensive care unit stay, and hospitalization period. Postoperative blood loss was lower in the MT-MVR group $(P \leq 0.001)$ than in the S-MVR group. There are no statistically significant differences in postoperative complications (superficial wound infection, stroke, delirium, pericardial tamponade, pleural puncture, acute kidney insufficiency, and implantation of pacemaker). The overall in-hospital mortality was $3.9 \%(P=0.6)$

Conclusion: The minimally invasive approach for RMS is feasible and has an excellent cosmetic effect without increasing the risk of surgical complications.

Keywords: Mitral Valve Stenosis. Mitral Valve-surgery. MiniThoracotomy. Coronary Artery Disease. Myocardial Ischemia. Prostheses and Implants. Hospitalization. Postoperative Complications.

\section{Abbreviations, acronyms \& symbols}

$\begin{array}{ll}\text { AKI } & \text { = Acute kidney insufficiency } \\ \text { CI } & =\text { Confidence interval } \\ \text { CPB } & =\text { Cardiopulmonary bypass } \\ \text { ICU } & =\text { Intensive care unit } \\ \text { MT-MVR } & =\text { Mitral valve replacement via minithoracotomy } \\ \text { MV } & =\text { Mitral valve } \\ \text { MVR } & =\text { Mitral valve replacement } \\ \text { NYHA } & =\text { New York Heart Association } \\ \text { RMS } & =\text { Rheumatic mitral valve stenosis } \\ \text { S-MVR } & =\text { Mitral valve replacement via sternotomy } \\ \text { SD } & =\text { Standard deviation }\end{array}$

'Department of Cardiac Surgery, Federal Center for Cardiovascular Surgery, Astrakhan, Russia.

${ }^{2}$ Department of Cardiovascular Surgery, Astrakhan State Medical University, Astrakhan, Russia ${ }^{3}$ Department of Cardiovascular Surgery, Pronto Socorro Cardiológico de Pernambuco - PROCAPE, Recife, PE, Brazil.

${ }^{4}$ Department of Thoracic and Cardiovascular Surgery, West German Heart and Vascular Center Essen, University Hospital of Essen, University Duisburg-Essen, Essen, Germany.

${ }^{*}$ Chernov I and Enginoev S contributed equally.

This study was carried out at the Federal Center for Cardiovascular Surgery, Astrakhan State Medical University, Astrakhan, Russia.

\section{INTRODUCTION}

Over the past few decades, minimally invasive surgery has revolutionized many aspects of the surgical treatment of mitral valve (MV) disease. Minimally invasive surgery is aimed at improving the cosmetic effect, reducing trauma, and a shorter period of hospitalization, while maintaining the safety and effectiveness of this access. Minimally invasive MV surgery using the videothoracoscopic approach was first introduced in the mid-1990s ${ }^{[1,2]}$. Since then, several studies have demonstrated the feasibility of minithoracotomy for MV interventions for selected patients in specialized high-volume centers ${ }^{[3-6]}$.

Rheumatic lesions of the MV remain the leading cause of mitral stenosis in endemic countries ${ }^{[7]}$. Only surgery (MV

Correspondence Address:

Soslan Enginoev

iD https://orcid.org/0000-0002-8376-3104

Department of Cardiac Surgery, Federal Center for Cardiovascular Surgery, Astrakhan State Medical University

4 Pokrovskaya rosha St., Astrakhan, Russia

Zip Code: 414011

E-mail: Soslan.Enginoev@gmail.com

Article received on November 17th 2019. Article accepted on January $11^{\text {th }}, 2020$. 
replacement or reconstruction) can be used to treat such patients. Nevertheless, the evidence for the use of mini access in such patients is insufficient.

In this article, we would like to share the experience of our clinic in the surgical treatment of rheumatic mitral valve stenosis (RMS). The aim of this study was to compare the immediate outcomes of a right-sided anterolateral minithoracotomy with those of sternotomy in RMS patients.

\section{METHODS}

\section{Study Population}

We present 128 patients with RMS who received mitral valve replacement (MVR) from 2011 to 2015 in our clinic. The median age of the patients was 53 years $(45 ; 56)$. The studied population included 43 (34\%) men; the preoperative mean left ventricular ejection fraction was $58.4 \pm 6.3 \%$, with $95 \%$ confidence interval of $57-62 \%$.

\section{Study Design}

This study is a retrospective review of prospectively collected data. Data were collected as part of the institutional Mitral Valve Surgery Database and included detailed information on the patients'demographics, baseline clinical characteristics, and their laboratory, echocardiographic, and hemodynamic parameters, as well as intraoperative variables and postoperative outcomes. The study was approved by the local ethics committee.

\section{Study Groups}

All the subjects were divided into two groups. Group 1, 78 patients who underwent MVR via minithoracotomy (MT-MVR), and Group 2, 50 patients who underwent MVR via sternotomy
(S-MVR). The choice of a surgical approach was based on the personal decision of a surgeon.

\section{Outcome Measures}

The endpoints were operation time, cardiopulmonary bypass (CPB) time, aortic cross-clamp time, mechanical ventilation time, intensive care unit (ICU) stay, hospital stay, volume of drain blood loss, major complications (stroke, delirium, superficial wound infection, tamponade, pericardial effusion, pleural puncture, rupture of the left ventricular posterior wall, acute kidney insufficiency, implantation of pacemaker), and in-hospital mortality.

\section{Exclusion Criteria}

- Redo procedure

- Hemodynamically significant coronary artery disease

- Concomitant cardiac surgery procedures

- Non-rheumatic MV disease

\section{Surgical Technique}

Preoperatively, all the patients underwent ultrasound duplex scanning of the femoral vessels and computed tomography of the aorta. Introductory anesthesia and maintenance of anesthesia did not differ from standard heart surgery procedures. All the patients also underwent intraoperative transesophageal echocardiography before the skin incision and at the end of the operation. All the procedures were performed using CPB with normothermic perfusion and Custodiol cardioplegia. The peripheral CPB cannulation of femoral vessels was performed in MT-MVR patients and the central cannulation in the S-MVR group.

In the MT-MVR group, access to the heart was carried out from the right anterolateral minithoracotomy in the $4^{\text {th }}$ intercostal space (Figure 1). A video camera, an aortic clamp, and a hook for exposing the left atrium were inserted through separate punctures.

\section{Statistical Analysis}

The data was analyzed using IBM SPSS Statistics software, version 25 (IBM Corp., Chicago, Illinois, United States of America). We used the Kolmogorov-Smirnov test to prove the data for normal distribution. Quantitative data was expressed as the mean and standard deviation for normally distributed variables and as the median and interquartile range for non-normally distributed variables. Categorical data was expressed as frequency and percentage. We used the Mann-Whitney $U$ Test to compare the mean values and the Fisher's exact test to examine the distribution of categorical variables between the groups. A value of $P<0.05$ was considered statistically significant.

Fig. 1 - Mitral valve replacement via minithoracotomy: an access. 


\section{RESULTS}

Demographic and preoperative clinical characteristics did not differ in both groups (Table 1). In all cases, MVR was performed because of the impossibility of the reconstruction of RMS. In the MT-MVR group, a mechanical prosthesis was implanted in $72 \%$ of cases; in the S-MVR group, it was implanted in 90\% of cases $(P=0.01)$. The type of prosthesis was selected regarding the guidelines and the patients' preferences, depending on the possibility of taking warfarin and monitoring International Normalized Ratio levels.

The total operation time and myocardial ischemia time did not differ in both study groups $(P>0.05)$, while the CPB time was lower in the S-MVR group than in the MT-MVR group $(P \leq 0.001)$. Intraoperative data is presented in Table 2. The duration of mechanical ventilation, ICU stay, and total hospital stay was similar in both groups. Postoperative blood loss was lower in the MT-MVR group than in the S-MVR group $(P \leq 0.001)$. There were no statistically significant differences in postoperative complications (Table 3). We also did not observe any difference in mortality between the two study groups.

\section{DISCUSSION}

In the mid-1990s, to minimize incision and trauma, various minimally invasive approaches were developed in MV surgery, including right parasternal approaches ${ }^{[8]}$ and superior and inferior hemisternotomy ${ }^{[9]}$. MT-MVR usually results in longer cross-clamp, CPB, and operative times. However, this fact does not affect the long-term survival and freedom of adverse events in MT-MVR compared with S-MVR ${ }^{[10]}$. Previous studies have reported the benefits of MT-MVR, including faster extubation; less postoperative pain, bleeding, and transfusion; better cosmetic results; and shorter duration of ICU and hospital stay (Figure 2) compared with S-MVR ${ }^{[11-15]}$. In contrast to these findings, we have not seen any difference regarding duration of ICU and inhospital stay.

There is still a lack of evidence regarding the use of the minimally invasive techniques for RMS. Chahal et al. ${ }^{[16]}$ published one randomized case-control study comparing right-sided minithoracotomy with sternotomy in patients with rheumatic MV lesions, during which it was shown that the minithoracotomy group had shorter ventilation time, hospitalization, and time

Table 1. Demographics and preoperative clinical characteristics.

\begin{tabular}{l|c|c|c}
\hline Variable & $\begin{array}{c}\text { MT-MVR (Group 1, } \\
\mathbf{n = 7 8 )}\end{array}$ & $\begin{array}{c}\text { S-MVR (Group 2, } \\
\mathbf{n = 5 0 )}\end{array}$ & $\boldsymbol{P}$-value \\
\hline Age (years), median (25 and 75 percentiles) & $51(44 ; 56)$ & $54(50 ; 56)$ & 0.09 \\
\hline Gender (female:male) & $50: 28: 00$ & $35: 15: 00$ & 0.56 \\
\hline Stroke, $\mathrm{n}(\%)$ & $4(5,1 \%)$ & $0(0 \%)$ & 0.15 \\
\hline NYHA II-IV class, $\mathrm{n}(\%)$ & $46(59 \%)$ & $35(70 \%)$ & 0.26 \\
\hline Pulmonary artery pressure (mmHg) & $44(38 ; 50)$ & $50(37 ; 60)$ & 0,06 \\
\hline Left ventricular ejection fraction (\%), median (25 and 75 percentiles) & $59 \pm 5.3(\mathrm{Cl}: 58 ; 60)$ & $58 \pm 7.5(\mathrm{Cl}: 56 ; 60)$ & 0.5 \\
\hline Left atrial volume (ml), median (25 and 75 percentiles) & $127(96 ; 162)$ & $135(105 ; 170)$ & 0,47 \\
\hline Atrial fibrillation, $\mathrm{n}(\%)$ & $37(47.4 \%)$ & $28(56 \%)$ & 0,37 \\
\hline
\end{tabular}

$\mathrm{Cl}=$ confidence interval; MT-MVR=mitral valve replacement via minithoracotomy; NYHA=New York Heart Association; S-MVR=mitral valve replacement via sternotomy

Table 2. Intraoperative variables.

\begin{tabular}{l|c|c|c}
\hline Variable & $\begin{array}{c}\text { MT-MVR (Group 1, } \\
\mathbf{n = 7 8 )}\end{array}$ & $\begin{array}{c}\text { S-MVR (Group 2, } \\
\mathbf{n = 5 0 )}\end{array}$ & P-value \\
\hline Mitral valve replacement, $\mathrm{n}(\%)$ & $78(100 \%)$ & $50(100 \%)$ & - \\
\hline Mechanical prosthesis, $\mathrm{n}(\%)$ & $56(72 \%)$ & $45(90 \%)$ & 0.01 \\
\hline Duration of the operation (min), mean \pm SD & $179 \pm 41(\mathrm{Cl}: 170 ; 189)$ & $167 \pm 42(\mathrm{Cl}: 155 ; 179)$ & 0.1 \\
\hline Cardiopulmonary bypass time (min), mean $\pm \mathrm{SD}$ & $119 \pm 34(112 ; 126)$ & $99 \pm 24(92 ; 106)$ & $\leq 0.001$ \\
\hline Aortic cross-clamp time (min), mean \pm SD & $77 \pm 24(71 ; 82)$ & $70 \pm 18(65 ; 75)$ & 0.09 \\
\hline Left atrium appendage closure, $\mathrm{n}(\%)$ & $8(10.3 \%)$ & $11(22 \%)$ & 0.08 \\
\hline
\end{tabular}

$\mathrm{Cl}=$ confidence interval; MT-MVR=mitral valve replacement via minithoracotomy; S-MVR=mitral valve replacement via sternotomy;

$\mathrm{SD}=$ standard deviation 
Table 3. Details of various postoperative complications.

\begin{tabular}{|c|c|c|c|}
\hline Variable & $\begin{array}{c}\text { MT-MVR (Group 1, } \\
\mathrm{n}=78 \text { ) }\end{array}$ & $\begin{array}{c}\text { S-MVR (Group 2, } \\
\mathrm{n}=50 \text { ) }\end{array}$ & $P$-value \\
\hline Myocardial infarction, n (\%) & $3(3.8 \%)$ & $0(0 \%)$ & 0.28 \\
\hline Stroke, n (\%) & $1(1.3 \%)$ & $3(6 \%)$ & 0.3 \\
\hline Pericardial effusion, n (\%) & $0(0 \%)$ & $3(6 \%)$ & 0.057 \\
\hline Mechanical ventilation time (hours), median (25 and 75 percentiles) & $9(7 ; 12)$ & $9(7 ; 12)$ & 0.78 \\
\hline Volume of drain blood loss (ml), median (25 and 75 percentiles) & $175(125 ; 231)$ & $275(213 ; 350)$ & $\leq 0.001$ \\
\hline Tamponade, n (\%) & $1(1.3)$ & $0(0 \%)$ & 1 \\
\hline Delirium, n (\%) & $3(3.8 \%)$ & $2(4 \%)$ & 0.65 \\
\hline Reoperation, n (\%) & $3(3.8 \%)$ & $0(0 \%)$ & 0.28 \\
\hline Pacemaker, n (\%) & $2(2.6 \%)$ & $0(0 \%)$ & 0.52 \\
\hline Superficial wound infection, n (\%) & $1(1.3 \%)$ & $3(6 \%)$ & 0.3 \\
\hline $\mathrm{AKI}, \mathrm{n}(\%)$ & $4(5.1 \%)$ & $5(3.4 \%)$ & 0.16 \\
\hline Rupture of left ventricular posterior wall, n (\%) & $1(1.3 \%)$ & $0(0 \%)$ & 1 \\
\hline Pleural punction, n (\%) & $9(12 \%)$ & $4(8 \%)$ & 0.76 \\
\hline Intensive care unit stay (hours), median (25 and 75 percentiles) & $20(17 ; 26)$ & $22(18 ; 36)$ & 0.38 \\
\hline Hospital stay (days), median (25 and 75 percentiles) & $12(10 ; 14)$ & $13(11 ; 15)$ & 0.2 \\
\hline Mortality, n (\%) & $3(3.8 \%)$ & $2(4 \%)$ & 0.6 \\
\hline
\end{tabular}

$\mathrm{AKI}=$ acute kidney insufficiency; MT-MVR=mitral valve replacement via minithoracotomy; S-MVR=mitral valve replacement via sternotomy

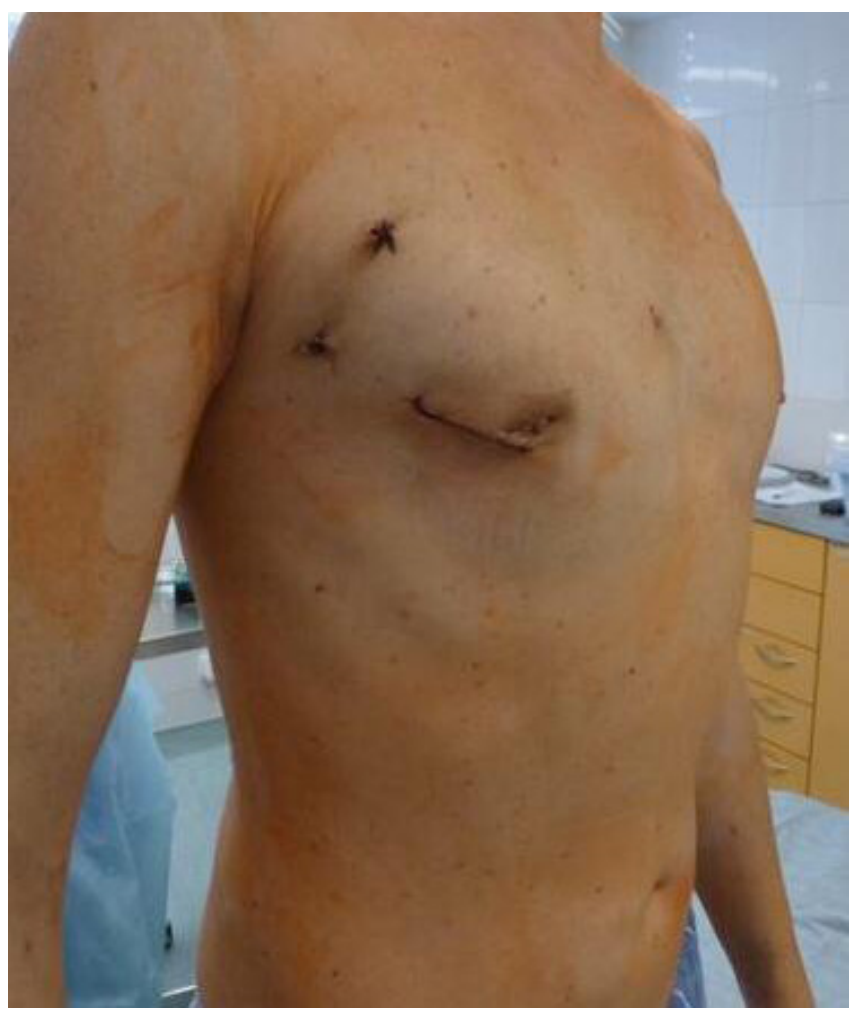

Fig. 2 - Mitral valve replacement via minithoracotomy: a final view.

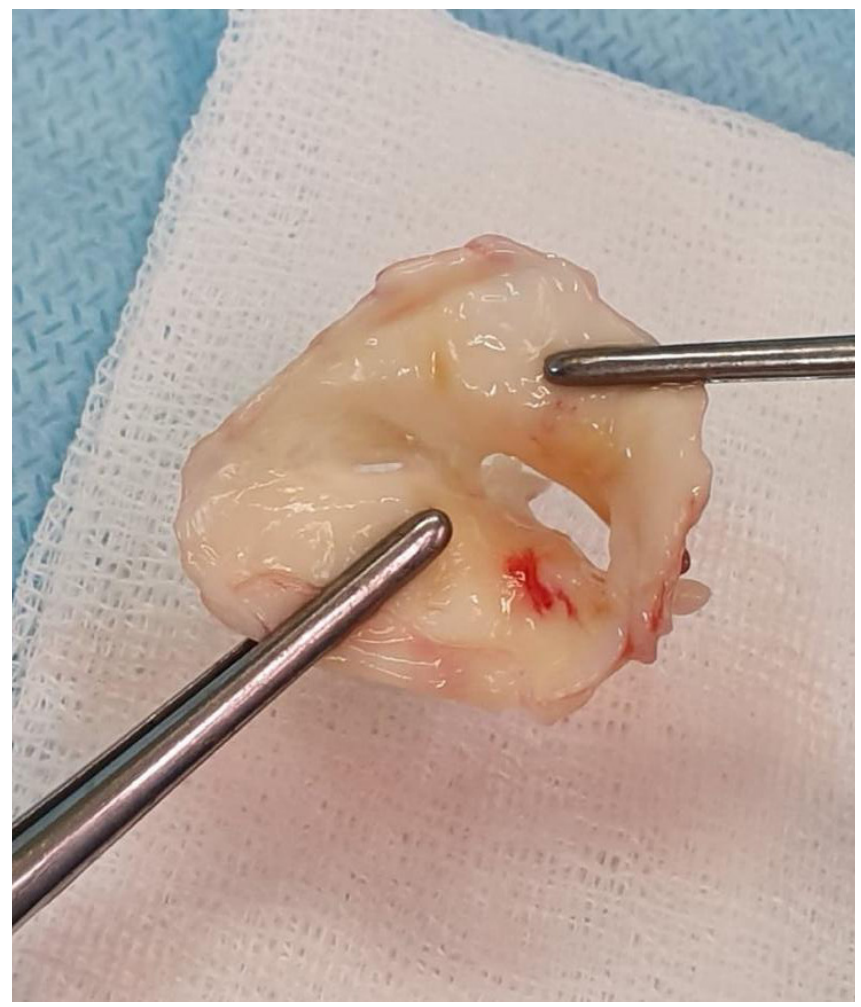

Fig. 3 - Excised rheumatic mitral valve. 
spent in the ICU. The minithoracotomy group also experienced less bleeding, pericardial effusion, postcardiotomy syndrome, and blood transfusions and required less blood substitutes than the sternotomy group. In our study, we included patients with isolated MV disease. Only valve replacement was performed. Valve repair is also possible in patients with RMS and shows acceptable midterm results ${ }^{[17]}$. However, it depends on the severity of MV calcification (Figure 3). The long-term durability of the valve repair for RMS has been discussed ${ }^{[7]}$. We demonstrated a non-inferiority of MT-MVR compared with S-MVR in middleaged patients with RMS regarding survival and postoperative complications.

\section{Study Limitations}

This study is a retrospective, nonrandomized analysis from a single medical center. The clinical decisions were made in a nonblinded fashion.

\section{CONCLUSION}

The minimally invasive approach for RMS is feasible and has an excellent cosmetic effect without increasing the risk of surgical complications. A prospective randomized study on a large sample of patients is needed for more routine use of this technique.

No financial support.

No conflict of interest.

\section{Authors' roles \& responsibilities}

IC

Substantial contributions to the conception or design of the work; or the acquisition, analysis, or interpretation of data for the work; drafting the work or revising it critically for important intellectual content; agreement to be accountable for all aspects of the work in ensuring that questions related to the accuracy or integrity of any part of the work are appropriately investigated and resolved; final approval of the version to be published

Substantial contributions to the conception or design of the work; or the acquisition, analysis, or interpretation of data for the work; drafting the work or revising it critically for important intellectual content; agreement to be accountable for all aspects of the work in ensuring that questions related to the accuracy or integrity of any part of the work are appropriately investigated and resolved; final approval of the version to be published interpretation of data for the work; drafting the work or revising it critically for important intellectual content; agreement to be accountable for all aspects of the work in ensuring that questions related to the accuracy or integrity of any part of the work are appropriately investigated and resolved; final approval of the version to be published

GM Substantial contributions to the conception or design of the work; or the acquisition, analysis, or interpretation of data for the work; drafting the work or revising it critically for important intellectual content; agreement to be accountable for all aspects of the work in ensuring that questions related to the accuracy or integrity of any part of the work are appropriately investigated and resolved; final approval of the version to be published

DT Substantial contributions to the conception or design of the work; or the acquisition, analysis, or interpretation of data for the work; drafting the work or revising it critically for important intellectual content; agreement to be accountable for all aspects of the work in ensuring that questions related to the accuracy or integrity of any part of the work are appropriately investigated and resolved; final approval of the version to be published

MPBOS Substantial contributions to the conception or design of the work; or the acquisition, analysis, or interpretation of data for the work; drafting the work or revising it critically for important intellectual content; agreement to be accountable for all aspects of the work in ensuring that questions related to the accuracy or integrity of any part of the work are appropriately investigated and resolved; final approval of the version to be published

AW Substantial contributions to the conception or design of the work; or the acquisition, analysis, or interpretation of data for the work; drafting the work or revising it critically for important intellectual content; agreement to be accountable for all aspects of the work in ensuring that questions related to the accuracy or integrity of any part of the work are appropriately investigated and resolved; final approval of the version to be published

Substantial contributions to the conception or design of the work; or the acquisition, analysis, or interpretation of data for the work; drafting the work or revising it critically for important intellectual content; agreement to be accountable for all aspects of the work in ensuring that questions related to the accuracy or integrity of any part of the work are appropriately investigated and resolved; final approval of the version to be published

\section{REFERENCES}

1. Chitwood WR Jr, Wixon CL, Elbeery JR, Moran JF, Chapman WH, Lust RM. Videoassisted minimally invasive mitral valve surgery. J Thorac Cardiovasc Surg. 1997;114(5):773-80; discussion 780-2. doi:10.1016/S0022-5223(97)70081-3.

2. Carpentier A, Loulmet D, Carpentier A, Le Bret E, Haugades B, Dassier P, et al. [Open heart operation under videosurgery and minithoracotomy. First case (mitral valvuloplasty) operated with success]. C R Acad Sci III. 1996;319(3):219-23. French.

3. McClure RS, Athanasopoulos LV, McGurk S, Davidson MJ, Couper GS, Cohn $\mathrm{LH}$. One thousand minimally invasive mitral valve operations: early outcomes, late outcomes, and echocardiographic follow-up. JThorac Cardiovasc Surg. 2013;145(5):1199-206. doi:10.1016/j.jtcvs.2012.12.070.

4. Arcidi JM Jr, Rodriguez E, Elbeery JR, Nifong LW, Efird JT, Chitwood WR Jr. Fifteen-year experience with minimally invasive approach for reoperations involving the mitral valve. J Thorac Cardiovasc Surg. 2012;143(5):1062-8. doi:10.1016/j.jtcvs.2011.06.036.

5. Modi P, Rodriguez E, Hargrove WC 3rd, Hassan A, Szeto WY, Chitwood WR Jr. Minimally invasive video-assisted mitral valve surgery: a 12-year, 2-center experience in 1178 patients. J Thorac Cardiovasc Surg. 2009;137(6):1481-7. doi:10.1016/j.jtcvs.2008.11.041. 
6. Enginoev ST, Koz'min DYu, Magomedov GM, Makeev SA, Ilov NN, Chernov II,Tarasov DG. [Comparative analysis of minithoracotomy and sternotomy in the pathology of mitral valve - the experience of one center]. Russ J Thorac Cardiovasc Surg. 2019; 61 (4):323-7 doi:10.24022/0236-2791-201961-4-323-327. Russian.

7. Zakkar M, Amirak E, Chan KM, Punjabi PP. Rheumatic mitral valve disease: current surgical status. Prog Cardiovasc Dis. 2009;51(6):478-81. doi:10.1016/j. pcad.2008.08.008

8. de Vaumas C, Philip I, Daccache G, Depoix JP, Lecharny JB, Enguerand $D$, et al. Comparison of minithoracotomy and conventional sternotomy approaches for valve surgery. J Cardiothorac Vasc Anesth. 2003;17(3):325-8. doi:10.1016/s1053-0770(03)00051-x.

9. Gaudiani VA, Grunkemeier GL, Castro LJ, Fisher AL, Wu Y. Mitral valve operations through standard and smaller incisions. Heart Surg Forum. 2004;7(4):E337-42. doi:10.1532/HSF98.20041023.

10. Javadikasgari H, Suri RM, Tappuni B, Gillinov AM. Minimally invasive mitral valve repair. Heart. 2018;104(10):861-7. doi:10.1136/heartjnl-2016-310774.

11. Suri RM, Thalji NM. Minimally invasive heart valve surgery: how and why in 2012. Curr Cardiol Rep. 2012;14(2):171-9. doi:10.1007/s11886-011-0244-8.
12. Schmitto JD, Mokashi SA, Cohn LH. Minimally-invasive valve surgery. J Am Coll Cardiol. 2010;56(6):455-62. doi:10.1016/j.jacc.2010.03.053.

13. Svensson LG, Atik FA, Cosgrove DM, Blackstone EH, Rajeswaran J, Krishnaswamy $\mathrm{G}$, et al. Minimally invasive versus conventional mitral valve surgery: a propensity-matched comparison. J Thorac Cardiovasc Surg. 2010;139(4):926-32.e1-2. doi:10.1016/j.jtcvs.2009.09.038.

14. Suri RM, Schaff HV, Meyer SR, Hargrove WC $3^{\text {rd }}$. Thoracoscopic versus open mitral valve repair: a propensity score analysis of early outcomes. Ann Thorac Surg. 2009;88(4):1185-90. doi:10.1016/j.athoracsur.2009.04.076.

15. Santana O, Reyna J, Grana R, Buendia M, Lamas GA, Lamelas J. Outcomes of minimally invasive valve surgery versus standard sternotomy in obese patients undergoing isolated valve surgery. Ann Thorac Surg. 2011;91(2):40610. doi:10.1016/j.athoracsur.2010.09.039.

16. Chahal AK, Gehlaut P, Johar S, Asija A, Arora D, Malhotra N, et al. A prospective randomized case-control study to evaluate mini right thoracotomy versus conventional sternotomy for mitral valve repair in rheumatic heart disease. World J Cardiovasc Surg. 2016;6(11):139-52. doi:10.4236/wjcs.2016.611021.

17. Salem A, Abdelgawad AME, Elshemy A. Early and outcomes of rheumatic mitral valve repair. Heart Surg Forum. 2018;21(5):E352-8. doi:10.1532/hsf.1978. 